\title{
Assessing the pre-hospital care preparedness to face mass casualty incident in Saudi Arabia in 2017-2018
}

\author{
Maged S. Alotaibi, MPH, Anas A. Khan, MBBS, MHA.
}

\begin{abstract}
الأهداف : تقييم الاستعداد في الرعاية (MCI) قبل المستشفيات

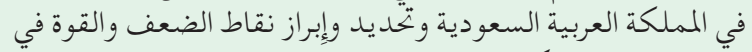

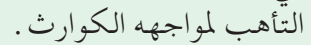

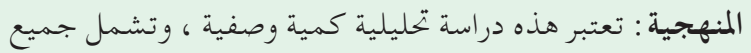

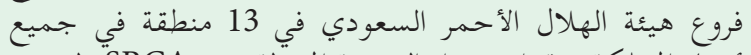

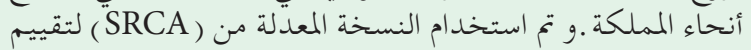

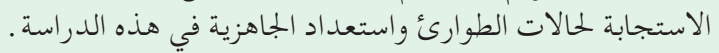
النتائج : تم العثور على أكبر عدد من سيارات الإِسعاف والسيارات

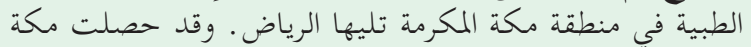

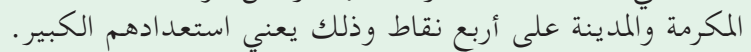

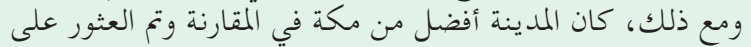

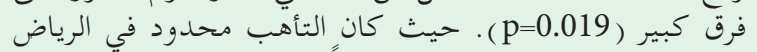

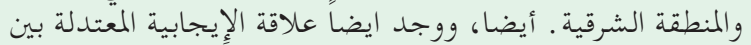

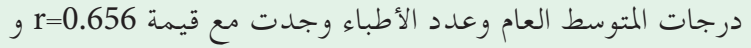
. $\mathrm{p}=0.015$

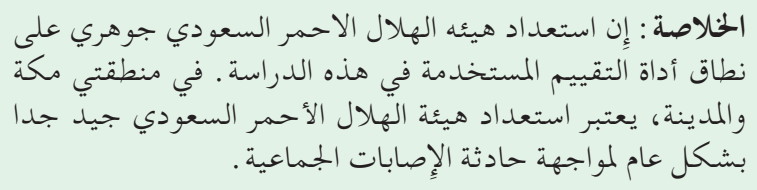

Objectives: To assess the mass casualty incident (MCI) preparedness of pre-hospital care providers in Saudi Arabia and to identify and highlight their strengths and weaknesses when responding to MCIs.

Methods: This cross-sectional descriptive quantitative analysis was conducted between January 2017 and 2018 and included all Saudi Red Crescent Authority (SRCA) general administration branches in 13 regions in Saudi Arabia. The modified version of the emergency medical specialists (EMS) incident response and readiness assessment (EIRRA) tool was used in this study.

Results: The Makkah region has the largest number of ambulances and medics vehicles, followed by Riyadh.
Makkah and Al Madinah Al Munawarah obtained a median score of 4 and showed substantial preparedness for MCIs. However, Al Madinah Al Munawarah showed higher level of MCI preparedness than Makkah, and a significant difference was found $(p=0.019)$. By contrast, Riyadh and the Eastern region showed limited MCI preparedness. In addition, a moderate positive correlation was observed between the overall median scores and the number of physicians ( $\mathrm{r}=0.656$ and $p=0.015$ ).

Conclusion: The SRCA showed substantial preparedness in Makkah and Al Madinah Al Munawarah. The SRCA were highly prepared to face MCIs.

Saudi Med J 2019; Vol. 40 (10): 1032-1039 doi:10.15537/smj.2019.10.24292

From the Disaster Management (Alotaibi), Saudi Red Crescent Authority, and from the Department of Emergency Medicine (Khan), College of Medicine and University Medical City, King Saud University, Riyadh, Kingdom of Saudi Arabia.

Received 24th March 2019. Accepted 26th May 2019.

Address correspondence and reprint request to: Dr. Maged S. Alotaibi, Department of Disaster Management, Saudi Red Crescent Authority, Riyadh, Kingdom of Saudi Arabia. E-mail: rooq_622@hotmail.com ORCID ID: orcid.org/0000-0003-3783-9195

$\mathrm{D}$ isaster can occur anytime and anywhere. The multiple causalities impact quality of life of several individuals and also burden the healthcare system. ${ }^{1}$ It primarily affects people's health and financial well-being. ${ }^{2}$ In 2015 , several major incidents occurred in Kingdom of Saudi Arabia (KSA). Approximately 2,000 people were left injured due to a natural disaster, while 1,200 were affected due to a manmade disaster. ${ }^{3}$ Health status gradually declines during a disaster, and the community requires outside assistance for smooth functioning. ${ }^{4}$ 
Mass casualty incident (MCI) has been described as any incident that affects a significant number of people. ${ }^{5}$ During MCI, the primary consideration is not the number of casualties but the surging capacity of the medical system to meet the healthcare needs of victims in this situation. ${ }^{6}$ Emergency medical service (EMS) personnel plays a crucial role in managing disasters for over 35 years. ${ }^{7}$ For this reason, their roles have been strengthened by the national association of EMS physicians in all the disaster cycle phases: mitigation, preparedness, response, and recovery. ${ }^{8}$

Mass casualty incident planning should include the proper distribution of resources by a push or pull model; push involves the distribution of all resources to the community, while pull involves the centralization of resources in the foremost place, and the patient is pulled to the central infrastructure. ${ }^{8}$ The level of preparedness varies in every community; some of the communities have response capabilities, while some lack response capabilities. ${ }^{9}$ Moreover, planning is essential for achieving a good outcome through successful management of disasters. Therefore, leaders must address the questions to ensure readiness and proper planning. ${ }^{10}$

In 2007, 56 passengers on board a motor coach to Telluride, Colorado, passed through the Phoenix Arizona route. When the driver took the right side of the road, the motor coach suddenly swerved and rolled over resulting mass casualties: 9 passengers died, and 43 sustained minor to serious injuries. ${ }^{11}$ In January 2004 , 13 cargo tankers crashed into 4 small cars, resulting mass casualties. In 2008, an MCI occurred in Mexican Hat, resulting 53 casualties. ${ }^{12}$ After that, the National Transportation Safety Board recommended that "the preparedness, readiness, and response system of the Federal Interagency Committee of Emergency Medical Services (FICEMS) should be evaluated and then a new guideline for EMS response to disaster conditions should be set and implemented to all states" ${ }^{11}$

In 2003, a study conducted to assess the public schools' preparedness to face MCI, and 307 schools in Arkansas were surveyed to evaluate their level of preparedness. Approximately $51.3 \%$ of school districts reported that they had not established a plan for managing MCI. On the contrary, $72.2 \%$ of school districts planned to conduct an emergency lockdown, while $91.2 \%$ planned to do an emergency evacuation. ${ }^{13}$

Disclosure. Authors have no conflict of interests, and the work was not supported or funded by any drug company.
A previous study was conducted in 13 private hospitals in KSA to evaluate their level of preparedness. A total of 12 (92.3\%) hospitals showed preparedness for external and internal disasters. Of them, 9 (69.2\%) made an agreement with other hospitals to accept more patients, whereas $4(30.8 \%)$ had no interhospital agreements. Moreover, disaster preparedness exercises and training have not been conducted in hospitals in the last 12 months. ${ }^{14} \mathrm{~A}$ recent study was conducted in KSA to evaluate the level of MCI preparedness in airports. This study showed that the airports have a sufficient number of EMS personnel who can respond to MCIs. However, within a relatively short period of time, they might $n$. level of preparedness to face MCI. Moreover, for pairwise comparisons across regions, the Mann-Whitney-Wilcoxon test was used. The Statistical Package for Social Sciences, version 21 (IBM Corp., Armonk, NY, USA) software was used to run these statistical tests

A total of 12 (92.3\%) hospitals showed preparedness for external and internal disasters. Of them, 9 (69.2\%) made an agreement with other hospitals to accept more patients, whereas $4(30.8 \%)$ had no interhospital agreements. Moreover, disaster preparedness exercises and training have not been conducted in hospitals in the last 12 months. $14 \mathrm{~A}$ recent study was conducted in KSA to evaluate the level of MCI preparedness in airports. is study showed that the airports have a su cient number of EMS personnel who can respond to MCIs. However, within a relatively short period of time, they might need help from the government agencies. 15

Only a few studies have examined the status of EMS in pre-hospital settings to determine their level of preparedness during MCI or disaster situations. To the best of our knowledge, we did not nd previous publications studying prehospital preparedness in Saudi Arabia. is study aimed to determine the level of readiness and preparedness of hospitals in KSA to provide prehospital medical care for MCI between 2017 and 2018.

Methods. This study was a cross-sectional descriptive quantitative analysis. e EMS Incident Response and Readiness Assessment (EIRRA) tool was used in this study. is tool was designed by the United States National Association of State Emergency Medical Services O cials (NASEMSO) to determine the level of preparedness for MCI. e latest edition was used during the study period. e executive director of NASEMSO, was contacted to request permission for the modi cation of EIRRA so it can be applicable in KSA. e modi ed copy was reviewed and approved by 5 experts before the implementation. e EIRRA tool includes 7 benchmarks: personnel, infrastructure, emergency care system, public awareness 
and noti cation, evaluation, mass casualty planning, and governance. ere are 31 indicators under all benchmarks. Each indicator has sub-indicators. Each sub-indicator is assessed using the following rating scale: $0=$ unknown, one $=$ none, $2=$ minimal, $3=$ limited, $4=$ substantial, and $5=$ comprehensive. Moreover, this tool was distributed to all Saudi Red Crescent Authority (SRCA) general administration branches in 13 regions in KSA.

The permission to conduct this study from SRCA had been obtained. Moreover, this study was approved by the King Saud Research Ethics Committee. Before the study was conducted, each participant was contacted by phone, and the purpose of the study was brie y described. Consent was obtained after explaining the importance of their contribution.

Statistical analysis. A descriptive analysis of the mean and median values was conducted. Non-parametric tests were the only statistic methods used to identify if there was a signi cant di erence between SRCA 13 branches in terms of level of preparedness to face MCI around KSA. In this study, the Kruskal-Wallis test was used to determine if all 13 regions had signi cant di erences in terms of level of preparedness to face MCI. Moreover, for pairwise comparisons across regions, the MannWhitney-Wilcoxon test was used. Statistical Package for Social Sciences, version 21 (IBM Corp., Armonk, NY, USA) software was used to run these statistical tests.

Results. The demographic data were as follows: the total number of centers, operation centers, dispatchers, ambulance drivers, EMT, EMS, field supervisors, physician, ambulance, and non-ambulance response vehicles in each region. These data varied per region. Riyadh, Makkah, Eastern region, and Al Madinah Al
Munawarah have the highest numbers, while the North borders have the lowest numbers as summarized in Table 1 and Figure 1.

The average number of centers is 33.5 centers. Figure 2 shows the number of centers in each region. Riyadh has the largest number of centers (89 centers, 21\%). Makkah and Eastern regions have 3 operation centers, while the remaining regions only have one operation center.

The average number of dispatchers is 30.7. Riyadh has the largest number of dispatchers $(n=87)$, while Aljof and Albaha regions have the smallest number of dispatchers $(n=15)$. The average number of ambulance drivers is 34. Riyadh and Makkah have the most significant number of ambulance drivers, whereas Najran has the lowest number of ambulance drivers.

The average number of EMTs is 354.3. Riyadh and Makkah have the largest number of EMTs, while the North borders have the lowest number of EMTs.

The average number of EMSs is 13.5. Riyadh and Makkah have the largest number of EMS, while Aljof, Tabuk, Albaha, and Najran have the lowest number of EMS. Moreover, there are no EMS in the North borders and Jazan regions.

The average number of physicians is 12.9. Riyadh has the largest number of physicians $(n=54)$ followed by Makkah $(n=46)$, while Najran, Albaha, Aljof, Jazan, and North borders have the smallest number of physicians $(\mathrm{n}=1)$.

The average number of ambulance cars is 67.7. Makkah has the largest number of ambulance cars $(\mathrm{n}=168,19 \%)$ followed by Riyadh $(145,16 \%)$ and Eastern region $(n=120,14 \%)$. By contrast, Hail $(n=30$,

Table 1 - The demographic data of 13 regions.

\begin{tabular}{|c|c|c|c|c|c|c|c|c|c|c|}
\hline $\begin{array}{l}\text { Name of } \\
\text { region }\end{array}$ & Center & $\begin{array}{c}\text { Operations } \\
\text { center }\end{array}$ & Dispatchers & Driver & EMTs & EMS & $\begin{array}{c}\text { Field } \\
\text { supervisors }\end{array}$ & Physicians & $\begin{array}{c}\text { Ambulance } \\
\text { cars }\end{array}$ & $\begin{array}{c}\text { Non-ambulatory } \\
\text { response cars }\end{array}$ \\
\hline Riyadh & 89 & 1 & 87 & 93 & 1206 & 53 & 10 & 54 & 145 & 12 \\
\hline Makkah & 84 & 3 & 38 & 90 & 950 & 40 & 13 & 46 & 168 & 13 \\
\hline Eastern Region & 61 & 3 & 52 & 56 & 257 & 20 & 13 & 30 & 120 & 8 \\
\hline Asir & 35 & 1 & 22 & 30 & 328 & 10 & 5 & 2 & 69 & 3 \\
\hline Al Madinah & 31 & 1 & 43 & 36 & 400 & 14 & 5 & 20 & 62 & 5 \\
\hline Tabuk & 24 & 1 & 24 & 27 & 245 & 4 & 5 & 5 & 52 & 1 \\
\hline Alqasim & 23 & 1 & 23 & 30 & 250 & 15 & 5 & 4 & 54 & 3 \\
\hline Jazan & 19 & 1 & 20 & 12 & 200 & 0 & 4 & 1 & 40 & 0 \\
\hline Najran & 15 & 1 & 27 & 5 & 198 & 5 & 5 & 1 & 50 & 7 \\
\hline Aljof & 14 & 1 & 15 & 17 & 160 & 1 & 7 & 1 & 28 & 0 \\
\hline Albaha & 14 & 1 & 15 & 17 & 140 & 5 & 5 & 1 & 30 & 0 \\
\hline Hail & 14 & 1 & 17 & 15 & 141 & 8 & 5 & 2 & 30 & 1 \\
\hline North border & 12 & 1 & 17 & 14 & 131 & 0 & 5 & 1 & 32 & 0 \\
\hline Grand total & 435 & 17 & 400 & 442 & 4606 & 175 & 87 & 168 & 880 & 53 \\
\hline
\end{tabular}




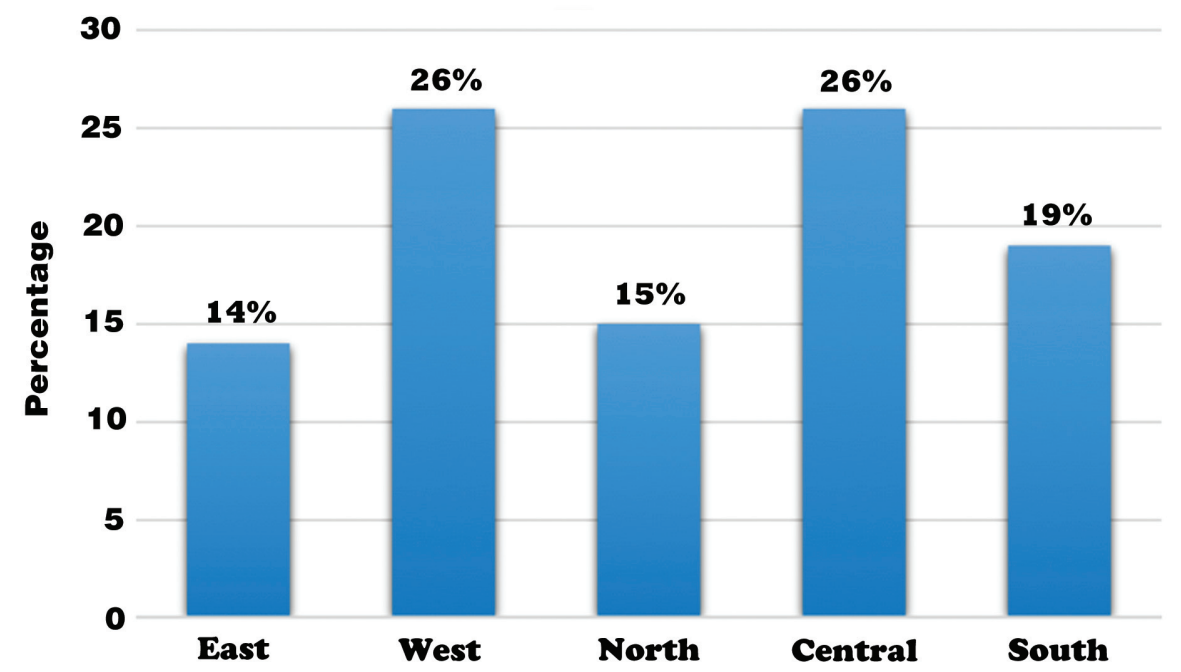

Figure 1 - The distribution of centers in Saudi Arabia (5 areas).

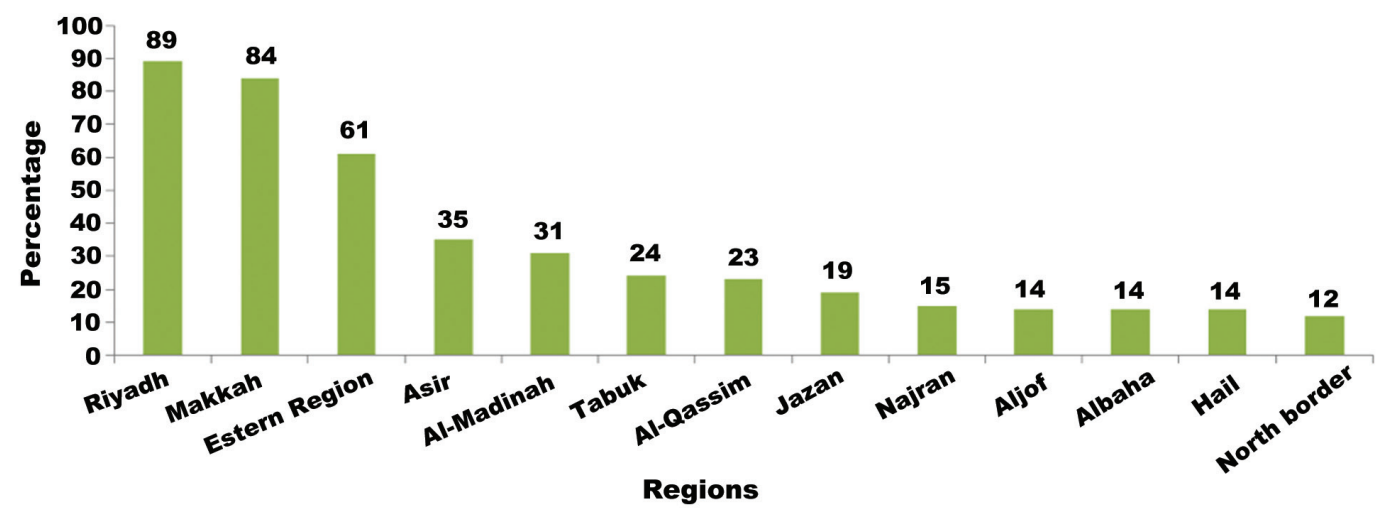

Figure 2 - Number of centers per region.

$3 \%)$ and Albaha ( $n=30,3 \%)$ have the lowest number of ambulance vehicles followed by Aljof ( $\mathrm{n}=28,3 \%)$.

Illustrated in Table 2, the median scores for each benchmark as well as the overall median scores across all regions in KSA. Makkah and Madinah obtained a median score of 4, which indicated that their emergency medical system is substantially equipped to manage MCIs. Riyadh, North borders, Eastern region, Tabuk, Jazan, Hail, and Qasim obtained a median score of 3, which indicated that their emergency medical system has limited capabilities to manage MCIs. The remaining regions obtained a median score of 2 , which indicated that their emergency medical system has minimal capabilities to manage MCIs.

Moreover, for the entire country, the results showed that the median for all benchmarks is the same (3) except for the evaluation benchmark, which is 2 . This finding indicates that there were no differences between the benchmarks across all regions in KSA.

Furthermore, the result of 5 areas (North, South, Central, East, and West) were analyzed. The West region has a median score of 4 , which indicated that their emergency medical system is substantially prepared for managing MCIs. The East, Central, and North regions have a median score of 3 , which indicated that their emergency medical system has limited capabilities to manage MCIs. While the South region had a median score of 2, which indicated that their emergency medical system has minimal capabilities to manage MCIs.

The correlation between the overall median scores of each indicator for all regions and the demographic variables are presented in Table 3. Results exhibited that a significant correlation was observed between the 
Table 2 - The emergency medical specialists incident response and readiness assessment results in 13 regions.

\begin{tabular}{|c|c|c|c|c|c|c|c|c|}
\hline Region & $\begin{array}{c}\text { Personnel } \\
100\end{array}$ & $\begin{array}{c}\text { Infrastructure } \\
200 \\
\end{array}$ & $\begin{array}{c}\text { Emergency care } \\
\text { system } 300\end{array}$ & $\begin{array}{c}\text { Public awareness } \\
\text { and notification } 400\end{array}$ & $\begin{array}{c}\text { Evaluation } \\
\text { of } 500\end{array}$ & $\begin{array}{c}\text { Mass causality } \\
\text { planning } 600\end{array}$ & $\begin{array}{l}\text { Governance } \\
700\end{array}$ & $\begin{array}{c}\text { Overall median } \\
\text { score }\end{array}$ \\
\hline Makkah & 3 & 4 & 4 & 4 & 3 & 4 & 4 & 4 \\
\hline Riyadh & 3 & 3 & 3 & 3 & 2 & 3 & 3 & 3 \\
\hline Al Madinah & 4 & 4 & 4 & 4 & 4 & 4 & 3 & 4 \\
\hline Aljof & 3 & 2 & 2 & 2 & 3 & 2 & 4 & 2 \\
\hline Asir & 4 & 3 & 2 & 2 & 2 & 2 & 2 & 2 \\
\hline Eastern Region & 3 & 3 & 3 & 3 & 2 & 4 & 4 & 3 \\
\hline Tabuk & 3 & 3 & 2 & 3 & 3 & 3 & 3 & 3 \\
\hline Albaha & 3 & 3 & 2 & 4 & 2 & 1 & 1 & 2 \\
\hline Najran & 3 & 1 & 2 & 1 & 2 & 2 & 2 & 2 \\
\hline Jazan & 3 & 2 & 3 & 2 & 3 & 3 & 1 & 3 \\
\hline Hail & 3 & 3 & 3 & 4 & 3 & 4 & 4 & 3 \\
\hline Alqasim & 3 & 3 & 3 & 3 & 2 & 3 & 2 & 3 \\
\hline North border & 3 & 3 & 3 & 4 & 2 & 3 & 3 & 3 \\
\hline Grand median & 3 & 3 & 3 & 3 & 2 & 3 & 3 & 3 \\
\hline
\end{tabular}

Table 3 - Correlations between the overall median score for each benchmark and demographic variables $(\mathrm{N}=13)$.

\begin{tabular}{|c|c|c|c|c|c|c|c|c|c|c|}
\hline Variables & Center & Operation center & Dispatcher & Driver & EMT & EMS & Supervisor & Physicians & $\begin{array}{l}\text { Ambulance } \\
\text { cars }\end{array}$ & $\begin{array}{c}\text { Medics } \\
\text { cars }\end{array}$ \\
\hline \multicolumn{11}{|l|}{ Spearman's rho } \\
\hline Correlation coefficient & 0.428 & 0.410 & 0.528 & 0.471 & 0.481 & 0.393 & 0.182 & $0.656^{*}$ & 0.504 & 0.410 \\
\hline Significance (2-tailed) & 0.144 & 0.164 & 0.064 & 0.104 & 0.096 & 0.184 & 0.551 & 0.015 & 0.079 & 0.164 \\
\hline
\end{tabular}

overall median scores and the number of physicians in the center ( $\mathrm{r}=0.656$ and $p=0.015)$.

There was a statistical difference in the level of MCI preparedness of the emergency medical system between Makkah and Riyadh regions $(p=0.038)$. Moreover, to determine which region has higher levels of MCI preparedness, a one-tailed test was performed and showed a $p=0.019$. This finding indicates that Makkah has higher levels of MCI preparedness than Riyadh.

There is significant difference in the level of MCI preparedness between Makkah and the Eastern region (Table 4, $p=0.038$ ). Moreover, to determine which region has higher level of MCI preparedness, a one-tailed test was performed and showed a $p=0.019$. This finding suggests that Makkah has higher levels of MCI preparedness than the Eastern region.

There was a statistical difference in the levels of MCI preparedness of the emergency medical system between Makkah and $\mathrm{Al}$ Madinah Al Munawarah regions ( $p=0.038)$. Moreover, to determine the level of MCI preparedness of the emergency medical system in each region, a one-tailed test was performed and showed a $p=0.019$. This finding suggests that the emergency medical system in Al Madinah Al Munawarah has higher level of preparedness for MCI than that in Makkah.
Furthermore, there was a statistical difference in the level of MCI preparedness of the emergency medical system between Riyadh and Al Madinah Al Munawarah $(p=0.038)$. There was a statistical difference in the level of MCI preparedness of the emergency medical system between West and East regions $(p=0.026)$. Additionally, there was a statistical difference in the level of MCI preparedness of the emergency medical system between West and South and West and Central regions ( $p=0.001)$.

There were no statistical differences in the level of MCI preparedness of the emergency medical system between the East and Central regions $(p=0.259)$. However, there was a statistical difference in the level of MCI preparedness of the emergency medical system between the East and South regions $(p=0.011)$.

There were no statistical differences in the level of MCI preparedness of the emergency medical system between the East and North regions $(p=0.259)$ and between the Central and South regions $(p=0.073)$. There were no statistical differences in the level of MCI preparedness of the emergency medical system between the Central and North regions $(p=1)$ and between the South and North regions $(p=0.073)$. 
Table 4 - Ranks and statistical tests ${ }^{\dagger, \neq}$ (Makkah-Eastern region) N=14.

\begin{tabular}{|c|c|c|c|c|c|}
\hline Region & Number & $\begin{array}{c}\text { Mean } \\
\text { rank }\end{array}$ & $\begin{array}{l}\text { Sum of } \\
\text { ranks }\end{array}$ & Mann-Whitney U & 15.500 \\
\hline Makkah & 7 & 8.79 & 61.50 & Wilcoxon W & 43.500 \\
\hline Eastern region & 7 & 6.21 & 43.50 & $\mathrm{Z}$ & -1.217 \\
\hline \multirow[t]{2}{*}{ Total } & 14 & & & $\begin{array}{l}\text { asymptotic significance } \\
\text { (2-tailed) }\end{array}$ & 0.223 \\
\hline & & & & Exact significance $\left[2^{*}\right.$ (one-tailed sig.)] & $0.038^{\ddagger}$ \\
\hline
\end{tabular}

$\dagger$ Grouping variable: region, $\ddagger$ Not corrected for ties, sig - significance, ${ }^{*}$ multiplication

Discussion. Saudi EMS students reported low perception of and attitudes toward their preparedness for disaster management. To assess the level of MCI preparedness of EMS in KSA, quantitative research is carried out. The findings in this study can be used as a reference to identify the causes of variations in the level of MCI preparedness among the 13 SRCA branches in KSA. Therefore, it will help in improving the preparedness level. The results of this study were divided into 2 parts: demographic results and assessment results.

The distribution of ambulance center and ambulance deployment is affected by the population and size of each region. ${ }^{16}$ The 2 regions with the largest number of centers, as shown in Figure 1, were Riyadh and Makkah. According to the 2016 Saudi statistical report, Riyadh and Makkah had the highest population among other regions. ${ }^{17}$ In Makkah and the Eastern regions, both had the highest number of operation centers. The SRCA organizational chart showed that both regions were divided into 3 units. Makkah region divided into 3 units; Holy Capital unit, Taif unit; and, Jeddah unit when Estern Region divided into AL Ahsa unit, Hafr Albateen Unit and Eastern region unit Each of these units had an operation center connected to the main operation center in both regions with the highest population. To operate an ambulance center, sufficient human resources are needed. Riyadh had the highest number of ambulance centers, which can be affected by the population size. The SRCA used the following 3 criteria to locate a new ambulance station: population size, medical records, which may support the demographic results suggesting that Riyadh had more ambulance stations and personnel than other regions. ${ }^{18}$ On the contrary, deployment of ambulance should minimize the population's transportation cost. ${ }^{16}$ Makkah had higher number of ambulance vehicles than Riyadh as shown in Table 1 . This can be due to the preparedness programs offered during Hajj and Umrah seasons, which are the largest annual religious mass gatherings in the world, and the KSA government has provided great attention to these programs. ${ }^{19}$
In the first benchmark, the entire KSA garnered a score of 3, which indicates lack of personnel. The limited number of EMS personnel might be due to the small number of paramedic graduates, as reported in Alaniz's study. ${ }^{20}$ In 2012, diploma programs were no longer offered in KSA. In order to become an EMS personnel, one should finish a bachelor's degree in paramedical science as a minimum requirement. ${ }^{21}$ Moreover, EMS personnel are trained on how to respond to MCIs. Alshamrani, ${ }^{22}$ reported that the SRCA only offered limited trainings to all EMS personnel, and they were asked to perform daily routine work such as basic life support, advanced cardiac life support, pre-hospital trauma life support, and international trauma life support. This finding supports the results of previous studies, which reported that the EMS personnel in KSA lacked training in disaster management. ${ }^{22}$ The medical directors are among the important key players in MCI management, should develop guidelines, and must participate in disaster preparedness planning. ${ }^{23}$ Saudi Red Crescent Authority lacked EMS consultants who can supervise the day-to-day work of all EMS personnel and assess disaster conditions. In this study, there was a moderate positive correlation between the overall median scores and the number of physicians in the center, which indicates a lower personnel benchmark score. Infrastructure was the second benchmark and one of the important factors in incident management. Infrastructure was determined in overall with limited score. Makkah and Al Madinah Al Munawarah were found to have substantial level of MCI preparedness due to the programs conducted during Hajj and Umrah seasons in these regions. In 2014 (1435 AH), a joint operation room was established during the Hajj season. All emergency agencies participated by sending one dispatcher to work there, and 911 was the universal number used for emergency calls.,19,24 The emergency care system benchmark had a lower overall median score. The results of Alsadhan's study, ${ }^{25}$ were similar to those reported in this study and suggested that the Saudi 
pre hospital care system need to improved. Moreover, Makkah and Al Madinah Al Munawarah were superior than other regions in terms of public awareness and notification and had a higher score in the public awareness benchmark than the remaining regions, which can be attributed to the programs conducted during Hajj season. Saudi Red Crescent Authority had a lower score in the evaluation benchmark, which examines whether the area has an effective evaluation system that can be used to provide a thorough review of the performance of emergency responders during MCIs. Myers, ${ }^{26}$ reported a few evidence and measures to review in the EMS performance system. Moreover, a study conducted by Alsadhan, ${ }^{25}$ showed that the evaluation system in KSA has limited capabilities to assess the status of pre hospital medical care. Riyadh obtained an overall median score of 3 , which indicates that this region had limited preparedness to handle MCIs. Riyadh is the most populous region in the KSA, with an estimated population of $8,002,100 .{ }^{17}$ A study conducted in 2011 in the United States of America showed that New York City has limited MCI preparedness. It has a total population of 8,244,910 and has the same status with Riyadh. ${ }^{17,27,28}$

Additionally, the Eastern region obtained a low score in the overall assessment. It is an important energy industrial region in KSA, where the biggest oil company (Saudi Aramco) in the world is located. The Eastern region is the largest province of KSA by area, with a total population of 4,780,619. ${ }^{17,29}$ The state of Alabama has the same industrial status, and the total population is very close to that of KSA's Eastern region $(4,780,135)$. It obtained a low score in the same evaluation method in the study conducted by Dia et al. ${ }^{27,30,31}$

The West region had a higher overall score, which may be due to the preparedness programs conducted during Hajj and Umrah seasons. The Saudi Arabian government pays attention to the safety of people attending the pilgrimage. Saudi Red Crescent Authority is a member of Hajj supreme committee. It includes all Saudi emergency agencies, and each of this organization had to prepare a Hajj emergency plan., ${ }^{3,32}$ In this study, Riyadh, Makkah, Al Madinah Al Munawarah, and the Eastern region were compared, and results showed that Al Madinah Al Munawarah was the most superior among the regions. A significant difference was observed between Makkah and Al Madinah Al Munawarah in terms of level of preparedness to face MCI. Despite that, both regions conducted the same Hajj preparedness program. The SRCA organization chart showed that Makkah was divided into 3 units based on its population size. Al Madinah Al Munawarah population that might the cause made Al Madinah Al Munawarah better than Makkah in the preparedness to face MCI. ${ }^{17,18}$

Study limitations. Pre-hospital medical care preparedness has not been tested before, and no baseline data were obtained for this study.

In conclusion, the SRCA prepared well to manage MICs in Makkah and Al Madinah Al Munawarah regions. Riyadh, North borders, Eastern region, Tabuk, Jazan, Hail, and Qasim had a median score of 3. The remaining regions had a median score of 2 . Some important aspects were not discussed in this study.

Furthermore, the SRCA should encourage EMS consultants to act as medical directors and supervise all EMS personnel. Moreover, more physicians should be deployed in all regions. Emergency medical specialists personnel preparedness should be improved by establishing a training program related to MCI. All EMS personnel should take the incident command system courses. Additionally, performing regular exercises and drills for MCI at least twice a year is important, and SRCA should take the leadership role. Saudi Red Crescent Authority should take into consideration the importance of implementing a unified management and restructure of the organizational chart in Makkah and Eastern regions. Privatization may be one of the solutions to increase the region's level of MCI preparedness.

\section{References}

1. Chartoff SE, Roman P. Disaster Planning. Treasure Island (FL): StatPearls Publishing; 2019.

2. Ashida S, Robinson EL, Gay J, Slagel LE, Ramirez MR. Personal disaster and emergency support networks of older adults in a rural community: changes after participation in a preparedness program. Disaster Med Public Health Prep 2017; 11: 110-119.

3. Tambo E, Fouad AM, Khater EI. Strengthening community emergency preparedness and response in threats and epidemics disasters prevention and management in Saudi Arabia. IJEM 2017; 13: 288-303.

4. Sundnes KO, Birnbaum ML. Health disaster management: guidelines for evaluation and research in the utstein style. Prehosp Disaster Med 2003; 17: 1-177.

5. Hsu EB, Jenckes MW, Catlett CL, Robinson KA, Feuerstein C, Cosgrove SE, et al. Effectiveness of hospital staff mass-casualty incident training methods: a systematic literature review. Prehosp Disaster Med 2004; 19: 191-199.

6. Doyle CJ. Mass casualty incident. Integration with prehospital care. Emerg Med Clin North Am 1990; 8: 163-175.

7. Cone D, Brice JH, Delbridge TR, Myers JB. Emergency medical services: clinical practice and systems oversight, 2 volume Set. Irving (TX): John Wiley \& Sons; 2014. 
8. Koh HK, Elqura LJ, Judge CM, Jacob JP, Williams AE, Crowther MS, et al. Implementing the cities readiness initiative: lessons learned from Boston. Disaster Med Public Health Prep 2008; 2: 40-49.

9. McHugh M, Staiti AB, Felland LE. How prepared are Americans for public health emergencies? Twelve communities weigh in. Health Aff (Millwood) 2004; 23: 201-209.

10. Fahlgren TL, Drenkard KN. Healthcare system disaster preparedness, part 2: nursing executive role in leadership. J Nurs Adm 2002; 32: 531-537.

11. Preparedness and response to a rural mass casualty incident: workshop summary. The national academies collection: Reports funded by National Institutes of Health. Washington (DC): National Academies Press (US); 2011.

12. Annual Report to Congress 2009. National Transportation Safety Board; 2009 [Updated 2019. Cited 2019 August 15]. Available from: https://www.ntsb.gov/about/Documents/ SPC1001.pdf

13. Graham J, Liggin R, Shirm S, Nation B, Dick R. Planning for a mass casualty incident in Arkansas schools. J Sch Health 2005; 75: 327-328.

14. Bin Shalhoub AA, Khan AA, Alaska YA. Evaluation of disaster preparedness for mass casualty incidents in private hospitals in Central Saudi Arabia. Saudi Med J 2017; 38: 302-306.

15. Ezreqat S, Khan A. Evaluation of a Saudi major airport's medical preparedness for mass casualty incident: a mixed-methodology study. MOJ Public Health 2017; 6: 346-352.

16. Harewood S. Emergency ambulance deployment in Barbados: a multi-objective approach. J Oper Res Soc 2002; 53: 185-192.

17. General Authority for Statistics. Saudi total population in 2016. [Updated 2019. Cited 2019 August 15]. Available from: https://www.argaam.com/ar/article/articledetail/id/452910

18. Saudi Red Crescent Authority. Annual Report Summary 2015. [Updated 2018. Cited 2017 March 15]. Available from: https://srca.org.sa/ar/Statistics/AnnualReport

19. World Health Organization. Summary report on the meeting of heads of medical missions on public health preparedness for Hajj, Jeddah, Saudi Arabia, 16-17 September 2014. World Health Organization. Regional Office for the Eastern Mediterranean; 2015.

20. Alanazi AF. Curriculum design of emergency medical services program at the College of applied Medical Sciences, King Saud bin Abdulaziz University for Health Sciences. Adv Med Educ Pract 2012; 3: 7-18.

21. Closure of Medical Institutes: Riyadh newspaper. [Cited 2019 September 22]. Available from: http://www.alriyadh. com/649903\#

22. AlShammari T, Jennings P, Williams B. Evolution of emergency medical services in Saudi Arabia. JEMTAC 2017; 2017: 4.

23. Role of the State EMS Medical Director/American College of Emergency Physicians, 2018. [Cited 2019 September 22]. Available from: https://www.acep.org/clinical---practicemanagement/role-of-the-state-ems-medical-director/\#sm.001w 1 hv8715suevossd 18c4a21ek6
24. National Centre for Security Operation. Unified Security Operations Centers (911). [Updated 2018. Accessed 2704 2018]. Available from: https://www.moi.gov.sa/ wps/portal/Home/sectors/4c/!ut/p/z1/jZFRb4IwFIX_ S1987gWq4GNDMouabGzBsb6QBqrpAq2Wss1_v2 K 2 h y U T b XIfevOdc9tz Mccl 51 p 8 q I N w y m jR-vsbX1SQEcICEm4S8vQANA_XKU2zMInnPUCpCvKSLwFSLarOWSUFc_LPIqARphP6He_ erhyKNypv_5APm3_IjVe3xriU1DvpxOnmNdGO_nlcFmbr hO6QWONTWvaGfzTRMLOYNBqr2SDelkPVrkzMkdpLx n3qJbe0fZoGQTegKjqTrhq5F4MrauE9SnwyT-MOfwFgCYe oNGOsTgPH5PgB5ja5K0sj11RlJ_nCFR2-AbE8_cu/dz/d5/ L2dBISEvZ0FBIS9nQSEh/

25. Alsadhan B, editor. Emergency early responders and EMS transition in Saudi Arabia: proposed model for system improvement: University of Pittsburgh (PA): University of Pittsburgh; 2015.

26. Myers JB, Slovis CM, Eckstein M, Goodloe JM, Isaacs SM, Loflin JR, et al. Evidence-based performance measures for emergency medical services systems: a model for expanded EMS benchmarking. Prehosp Emerg Care 2008; 12: 141-151.

27. Dia G BA, Dennis B, Mark B, William C, Richard C, Kelly H. EMS incident response and readiness assessment (EIRRA): a self-assessment tool to measure the level of EMS preparedness for responding to a highway mass casualty incident or other large scale emergency. National Association of State EMS Officials. [Updated 2011. Cited 2019 September 22]. Available from: https://www.ems.gov/pdf/2011/July2011/8-EMS. Incident.Response-Readiness.Assessment.(EIRRA).pdf

28. New York City Department of City Planning. ACS demographic and housing estimates New York City and Boroughs. 2011 American community survey population Division; NYC Department of City Planning. [Updated 2011. Cited 2019 September 22]. Available from: https://www1.nyc. gov/assets/planning/download/pdf/data-maps/nyc-population/ acs/boro_demo_2011_acs.pdf

29. Abro MMQ, Khurshid MA, Aamir A. Corporate Social Responsibility (CSR) practices: the case of Saudi Aramco. Journal of Competitiveness Studies 2016; 24: 79-90.

30. The top states in America's 10 leading industries 1994. [Cited 2018 May 03]. Available from: http://foundersguide.com/topstates-among-the-10-major-industries-in-us/

31. Total population/state of Albama 2011. [Cited 2018 May 03]. Available from: https://www.census.gov/quickfacts/AL

32. Saudi Supreme Haj Committee 2018 [Updated 2018. Cited 2018 April 28]. Available from: https://www.makkah.gov.sa/ page/hajj 